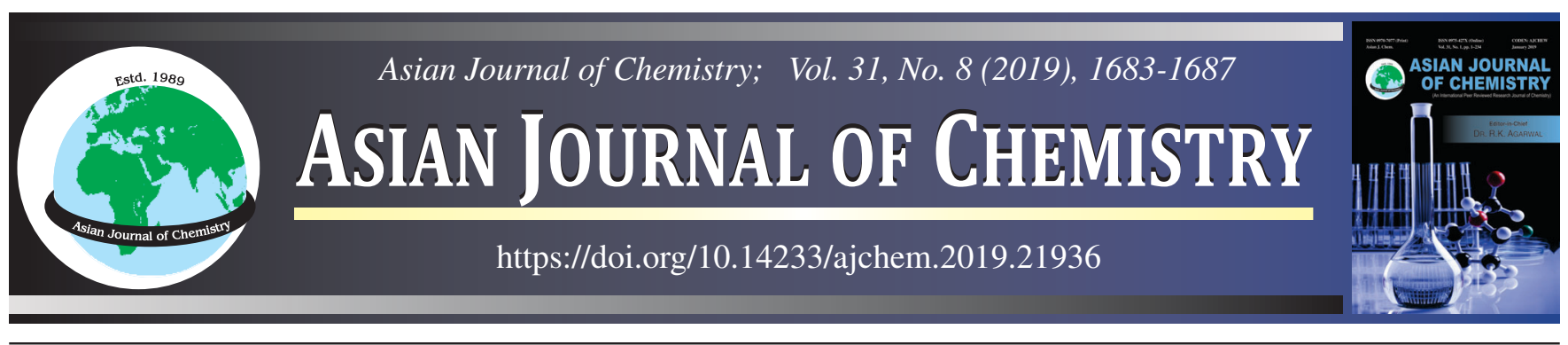

\title{
trans Effect of Amino-Chloro-Platinum Complexes and the Reaction of Cisplatin with Guanine: A Theoretical Study
}

\author{
Mohamed A. Makhyoun* and RaghdaA A. Massoud
}

Chemistry Department, Faculty of Science, Alexandria University, 21525 Alexandria, Egypt

*Corresponding author: E-mail: makhyoun2@yahoo.com

Received: 14 January 2019; Accepted: 12 March 2019; Published online: 28 June 2019;

The reactions of cis-[ $\mathrm{Pt}\left(\mathrm{NH}_{3}\right)_{2} \mathrm{Cl}$-cytosine] to form cis and trans dichloro products have been investigated theoretically by the aid of DFT method at the B3LYP/LANL2DZ level. It has been demonstrated by the estimation of activation energies the labile nature of the $\mathrm{NH}_{3}$ in the trans position. Investigation of the reaction between guanine and cis-platin was also performed. The transition states of the first two reactions were found by involving a restrained optimization of the reactant complexes and the product complexes.

Keywords: DFT calculations, trans-Effect, Cisplatin-guanine complex.

ᄂ - - - - - - - - - - - - - - - -

\section{INTRODUCTION}

Platinum complexes have attracted considerable scientific and clinic interest, they are amongst the most widely used anticancer agents. The square planar compound cis-dichlorodiamine platinum (cis-DDP, cis-platin) was recognized as an active substance in antitumor treatment [1]. The anticancer drug cis-platin reacts with DNA in the nucleus of a cell, this prevents the cell from dividing. Normal cells can repair the DNA damage, but cancer cells are unable to repair the damage and soon die, so it is supposed to exert their antitumor activity by impairing the DNA normal functions [2]. Since the discovery of this activity, much progress has been made in understanding its mode of action and details of the mechanism leading to antitumor activity are now well established [3].

Due to the chemotherapeutic importance of cis-platin and to improve clinical effectiveness of the Pt-based chemotherapy, continuing search for the novel Pt drugs is inevitable and several complexes with nucleobases, which have revealed a high anticancer activity in vitro as compared to cis-platin, were synthesized from the parent or related compounds [4-8].

The discovery of the antitumor activity of cis-platin has simulated great interest in platinum-nucleic acid interactions [4]. The coordination of $c$ is-platin to DNA purine bases represents a frequent topic of many recent papers. Despite the vast body of research on platinum drugs; their mechanisms of action and a large amount of experimental work devoted to Pt-DNA interactions [3,9], there was a lack of information about its structure and energetic and ab initio calculations were rather rare in this field. This is partly due to the fact that, computational studies were limited by the difficulty in theoretically describing transition metals and their complexes. Today, various basis sets suitable for the description of metal complexes are readily available. Therefore, theoretical calculations complement the experimental studies and they can offer valuable insights and possibly provide a foundation for new strategies.

The studies in this paper are organized into two sections. The first section covers studies on cis-platin adducts (cis$\left.\left[\mathrm{PtCl}\left(\mathrm{NH}_{3}\right)_{2} \text {-cytosine }\right]^{+}\right)$. The ammonia molecule trans to chlorine in cis-platin or other molecules of analogous structure can easily be replaced by attacking groups as choride ion at room temperature (the trans effect). For example, it was shown that the reaction (below) exhibits marked lability of ammonia group [4].

$$
\begin{aligned}
& \text { cis- }\left[\mathrm{PtCl}\left(\mathrm{NH}_{3}\right)_{2}-1 \text {-methylcytosine }\right]^{+}+\mathrm{Cl}^{-} \longrightarrow \\
& \text { trans }\left[\mathrm{PtCl}_{2}\left(\mathrm{NH}_{3}\right)-1 \text {-methylcytosine }\right]+\mathrm{NH}_{3}
\end{aligned}
$$

Another example of the trans effect comes from the study of cis and trans isomers of $\left[\mathrm{Pt}\left(\mathrm{NH}_{3}\right)_{2} \mathrm{Cl}-\mathrm{NH}_{2}\left(\mathrm{CH}_{2}\right)_{\mathrm{n}} \mathrm{NH}_{2}\right]\left(\mathrm{NO}_{3}\right)$, using ESI/SID tandem mass spectrometry [10]. The ESI/SID data and energy-resolved mass spectra show that the position of the chloride plays a significant role in the fragmentation of these ions. The cleavage of the Pt-N bond trans to chloride

This is an open access journal, and articles are distributed under the terms of the Attribution 4.0 International (CC BY 4.0) License. This license lets others distribute, remix, tweak, and build upon your work, even commercially, as long as they credit the author for the original creation. You must give appropriate credit, provide a link to the license, and indicate if changes were made. 
was the most favourable pathway for both isomers. The second section deals with small models to probe the detailed electronic structures of cis-platin and cytosine and then we studied their interaction using quantum chemistry methods which play an important role in the elucidation of their structures. Parallel studies aimed at obtaining transition state structures and energies in the gas phase. This work is the continuation of efforts to systematically synthesize and characterize cis-platin complexes with nucleobase model components in order to get a better understanding of the cis-platin interaction with cytosine.

In this work we report the reactions of cis- and trans$\left[\mathrm{PtCl}\left(\mathrm{NH}_{3}\right)_{2} \text {-cytosine }\right]^{+}$with chloride ions and then study the reaction of cytosine with cis-platin.

\section{EXPERIMENTAL}

In the first part of our study, we will focus on the ion cis-[ $\mathrm{Pt}\left(\mathrm{NH}_{3}\right)_{2} \mathrm{Cl}$-cytosine $]^{+}$[4] (ion 1). Two reactions pathways will be considered involving this ion with an attacking chloride ion: (i) The formation of cytosine-amine-cis-dichloro-platinum molecule (Compound 2) plus free ammonia. (ii) (Compound 3) plus free ammonia. These two reactions will be investigated theoretically adopting the Gaussian software [11], at the B3LYP/LANL2DZ level of computations.

Our calculations in the second part involved in explaining why the aquo derivative of cis platin favour the attack at N7 rather than $\mathrm{N} 3$ of guanine.

All of the studies on the interaction of cisplatin with guanine were mainly concerned with the energetic aspects of Pt complexation. In the second part of our study, we performed geometry optimizations of the complexes of cisplatin with 3- and 7positions of guanine using Gaussian software [11], at the B3LYP/LANL2DZ level of theory. All the geometry optimizations were followed by frequency calculations at the same level of theory. Vibrational frequency calculation results were used to confirm proper convergence to local minima and maxima for equilibrium and transition state geometries respectively and to derive the zero-point energy (ZPE). The absence of negative frequencies assured that the optimized structures correlate to energy minima.

\section{RESULTS AND DISCUSSION}

The main interest in the first part of our study comes from the question: Why the reaction of cis[Pt-diamine-chlorocytosine] with a chloride ion [4], gives easily the trans[Ptamine-dichloro-cytosine] and not the cis dichloro isomer? This can be attributed to the trans effect known for other reactions, but this question was not answered at the quantitative level. To answer this question by computational quantum chemistry, the total energies of the geometry optimized separate molecules: $\mathrm{NH}_{3}, \mathrm{Cl}^{-}$, cisplatin and trans-dichloro derivatives of platinum cytosine complex were calculated. Beside that, the reactant and product complexes were also calculated (Table-1). It is also crucial to calculate the transition state comp-lexes of reactions (1) and (2) by applying special conditions during the calculations [12]. It was found in most cases, the separate molecules are of more positive energy than the reactants complex (Figs. 1 and 2) or products complex, which are manifested in Table-1 and this was observed in other reported work [13].

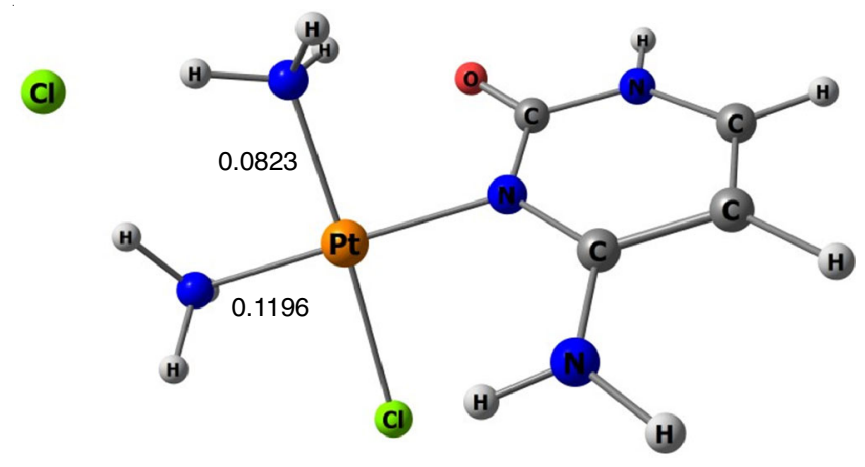

Fig. 1. Reactant Complex due to the reaction of chloride ion with: [Ptcytosine-cis-diamine-Cl] ${ }^{+}$. $\mathrm{H}$ : blue, $\mathrm{C}$ : yellow, $\mathrm{N}$ : violet, $\mathrm{O}$ : red, $\mathrm{Pt}$ : dark blue

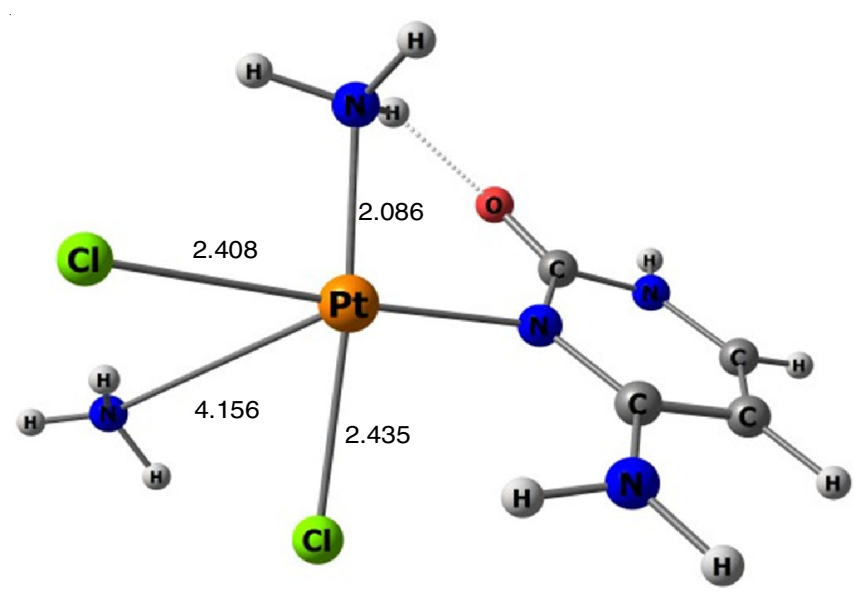

Fig. 2. Transition state complex due to the reaction of $\mathrm{Cl}^{-}$with [Pt-cytosinecis-diamine- $\mathrm{Cl}]^{+}$to form [Pt-cytosine-cis- $\left.\mathrm{Cl}_{2} \mathrm{NH}_{3}\right]$ Bond distances are shown around platinum. Activation energy $=16.32 \mathrm{Kcal} / \mathrm{mol}$. $\mathrm{Pt}$-ammonia $=4.156 \mathrm{~A}$, indicating that it is going to be replaced by $\mathrm{Cl}^{-}$ion

The transition state complex has two ammonia molecules and two chloride ions attached to the platinum center forming penta coordinated structure (Fig. 3).

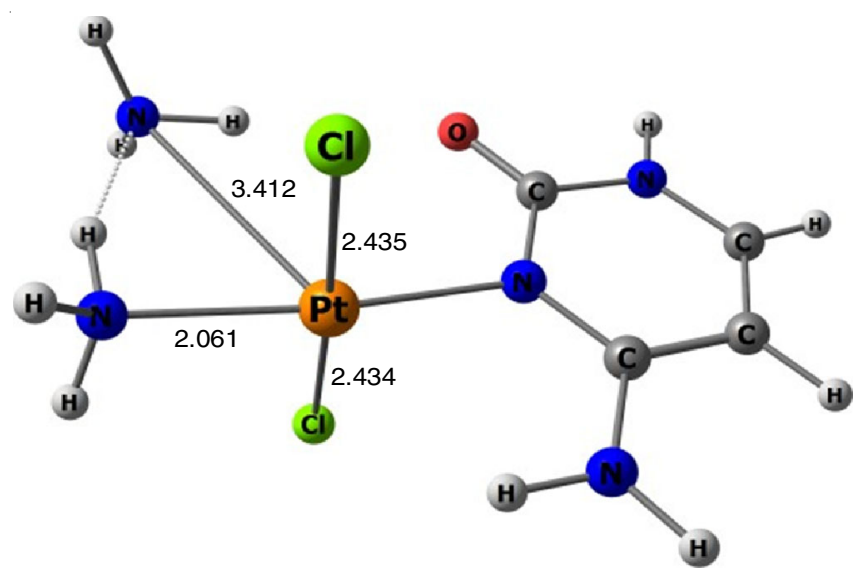

Fig. 3. Transition state complex structure due the reaction of $\mathrm{Cl}^{-}$with $[\mathrm{Pt}-$ cytosine-cis-diamine-Cl] ${ }^{+}$to form [Pt-cytosine-trans $-\mathrm{Cl}_{2} \mathrm{NH}_{3}$ ] Activation energy $=1.82 \mathrm{Kcal} / \mathrm{mol}$

We have two transition complexes of energies given in Table-1. The presence of two different transition state molecules of the same molecular formula depends mainly on the expected products. 


\begin{tabular}{|c|c|c|c|}
\hline \multicolumn{4}{|c|}{$\begin{array}{c}\text { TABLE-1 } \\
\text { TOTAL ENERGIES OF DIFFERENT SPECIES ALONG REACTION PATHS (1) AND (2) } \\
\text { IN HARTREE (ZERO POINT CORRECTIONS INCLUDED) }\end{array}$} \\
\hline \multicolumn{4}{|c|}{ Path (1) } \\
\hline Separated ion (1) plus $\mathrm{Cl}^{-}$ & Ion $(\mathbf{1})+\mathrm{Cl}^{-}$complex reactant & Transition state ion $(\mathbf{1})+\mathrm{Cl}^{-}$; Config. A & Activation energy $(\mathrm{Kcal} / \mathrm{mol})$ \\
\hline-656.8462 & -657.0294 & -657.0034 & 16.32 \\
\hline \multicolumn{4}{|l|}{$\Delta \mathrm{S}^{\#}=11.4 \mathrm{cal} / \mathrm{mol}-\mathrm{kel}$ vin } \\
\hline \multicolumn{4}{|c|}{ Path (2) } \\
\hline Separated ion (1) plus $\mathrm{Cl}^{-}$ & Ion $(\mathbf{1})+\mathrm{Cl}$ complex reactant & Transition state ion $(\mathbf{1})+\mathrm{Cl}^{-}$; Config. B & Activation energy (Kcal/mol) \\
\hline-656.8462 & -657.0294 & -657.0265 & 1.82 \\
\hline
\end{tabular}

From Table-1, the activation energies of the two mentioned reactions has been approximated by:

$$
\begin{gathered}
\mathrm{E}_{\text {Total }}^{\prime}(\text { transition state complex })- \\
\mathrm{E}_{\text {Total }}^{\prime}(\text { reactants complex })
\end{gathered}
$$

where $\mathrm{E}_{\text {total }}$ is total energy corrected for zero point vibrations.

Also the entropy change of the transition state of the two reactions (Table-1) is in favour of the formation of a pentacoordinated complex structure configuration B. In Fig. 1, the bond populations of the ammonia molecules are given for the two platinum ammonia bonds. The value of 0.0823 trans to chlorine indicates. Also the labile nature of this bond compared to the other platinum ammonia bond. The vibrational frequency of a bond indicates how much the the strength of the bond. In present case, the wavenumber for the Pt-N cis to chlorine in parent compound is $490.3 \mathrm{~cm}^{-1}$, while the wavenumber for $\mathrm{Pt}-\mathrm{N}$ trans to chlorine is $469.3 \mathrm{~cm}^{-1}$, which is also evidence of the weaker strength of the latter.

Also the activation energy for the formation of trans$\left[\mathrm{PtCl}_{2}-\left(\mathrm{NH}_{3}\right)\right.$-cytosine]; was found to be less than $1 \mathrm{Kcal} / \mathrm{mol}$ which clearly indicates the labile property of ammonia trans to chlorine in cis- $\left[\mathrm{Pt}\left(\mathrm{NH}_{3}\right)_{2} \mathrm{Cl} \text {-cytosine }\right]^{+}$ion in HF/LANL2DZ run (Fig. 4). On the other hand, the activation energy of the cis-isomer; was found to be approximately $26 \mathrm{Kcal} / \mathrm{mol}$ (Fig. 5).

A good explanation of this phenomena was explained in several places. Some ligands weaken the M-L bond trans to them in the ground state and thus by facilitating the substitution. For example, strong $\sigma$-donors like $\mathrm{H}^{-}, \mathrm{I}^{-}, \mathrm{Me}^{-}, \mathrm{PR}_{3}$, etc., destabilize the M-L bond trans to themselves and thus by bringing the easy substitution of that ligand and also occured by the stabilization of transition state.

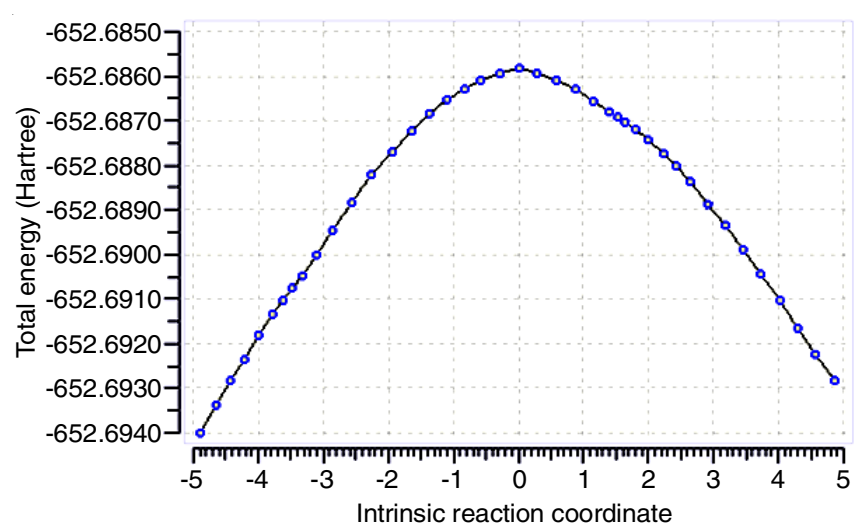

Fig. 4. Potential energy curve of the formation of Pt-am-trans-Cl - -cytosine Method $=$ RHF/LANL2DZ. Activation energy $<1 \mathrm{Kcal} / \mathrm{mol}$

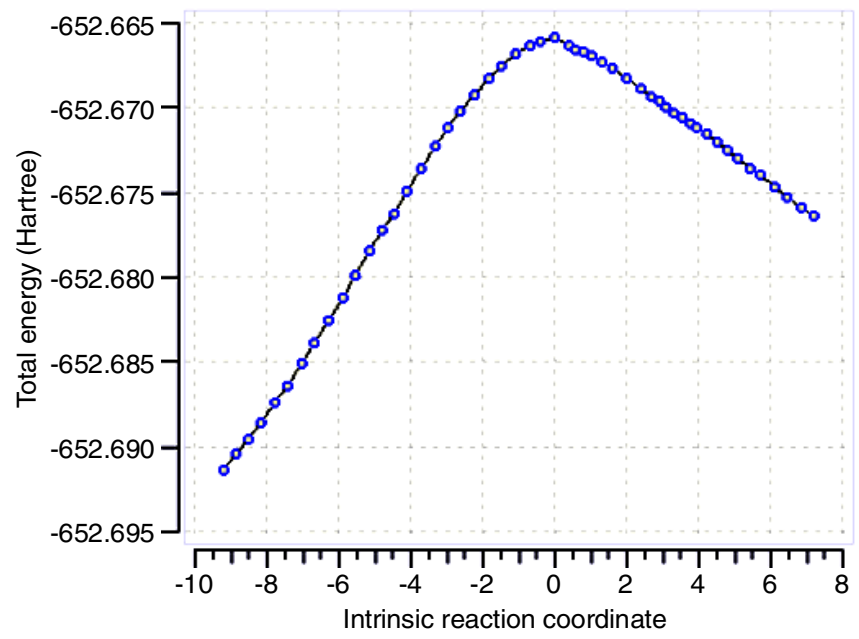

Fig. 5. Potential energy curve of the formation of Pt-am-cis- $\mathrm{Cl}_{2}$-cytosine. Method $=$ RHF/LANL2DZ. Activation energy $\sim 26 \mathrm{Kcal} / \mathrm{mol}$

Other confirmations for the trans effect come from the calculated intrinsic reaction coordinates of the two reactions which are represented in Figs. 4 and 5 [14]. The mechanism of the trans substitution is very simple. The attacking chloride ion comes through a path perpendicular to the plane gathering the $\mathrm{Pt}+\mathrm{Cl}+\left(\mathrm{NH}_{3}\right)$, to avoid steric hindrance. Also the $\mathrm{d}_{z^{2}}$ orbital perpendicular to this plane is half filled allowing $\sigma$ bond formation with the $p$-orbital of the chloride ion. Thus forming transition state complex of penta-coordinating structure. after that the ammonia molecule in the trans position with the weaker bond (bond population $=0.0823$ ) will leave. The orbital population of the different $d$ - of platinum are given below.

$$
\mathrm{d}_{\mathrm{z}^{2}}: 1.093, \mathrm{~d}_{\mathrm{x}^{2}-\mathrm{y} 2}: 1.678, \mathrm{~d}_{\mathrm{yz}}: 1.926, \mathrm{~d}_{\mathrm{xy}}: 1.930, \mathrm{~d}_{\mathrm{xz}}: 1.994
$$

These populations are calculated after the rotation of the coordinate system as to make the platinum lying only along the $\mathrm{z}$ axis.

Since the total energies of reactants complex and products complex of reaction (II) are accidentally nearly the same (Table1), so that the intrinsic reaction coordinates curve is symmetric for reaction (II) (Fig. 4).

In the second part we have investigated the reactions involving the interaction between cis-platin and guanine. This reaction is interesting because cisplatin is transformed into aquo complex loosing one chloride ion in human cell and attacks the 7-position of guanine in the DNA strand [15]. This is believed to be the first step towards exhibiting antitumorous effect. The choice of guanine over adenine was discussed and 
proved theoretically [3]. There are two centers of interest in guanine were the aquo complex of cisplatin can attack. These are the 3- and 7-positions. So why the aquo complex prefer the 7-position over the 3-position. Our calculations show that through geometry optimizations of the two transition states of the two possibilities that the compound formed at the 3-position is favoured $\left(\Delta \mathrm{E}_{\text {trans }}=17.54 \mathrm{Kcal} / \mathrm{mol}\right)$ contrary to experimental finding [4]. The other possibility has $\Delta \mathrm{E}_{\text {trans }}=$ 31.75. Another confirmation that the attack should be occurred at 3-position is the atomic charges of free guanine which are N3 $=-0.078(-0.631)$ and N7 $=-0.040(-0.484)$. Values are due to Mulliken atomic charge, values in parantheses are natural atomic charges.

There is a factor, which prevent the attack of aquo-cisplatin at the 3-position. This is due to the relatively steric hindrance inside the DNA strand (Fig. 6). The space around the 3-position is relatively small to allow such attack. There may be other factors. When aquo-cisplatin attacks at the 7-position of guanine we have two possibilities either the reaction involves removal of water to form the compound or removal of chloride ion Geometry optimizations of two possible products indicate that the product where the water molecule removed is more stable than the other structure by about $15.7 \mathrm{Kcal} / \mathrm{mol}$ which is consistent with experimental findings [4]. (It is noted that the reactants are the same in both cases).

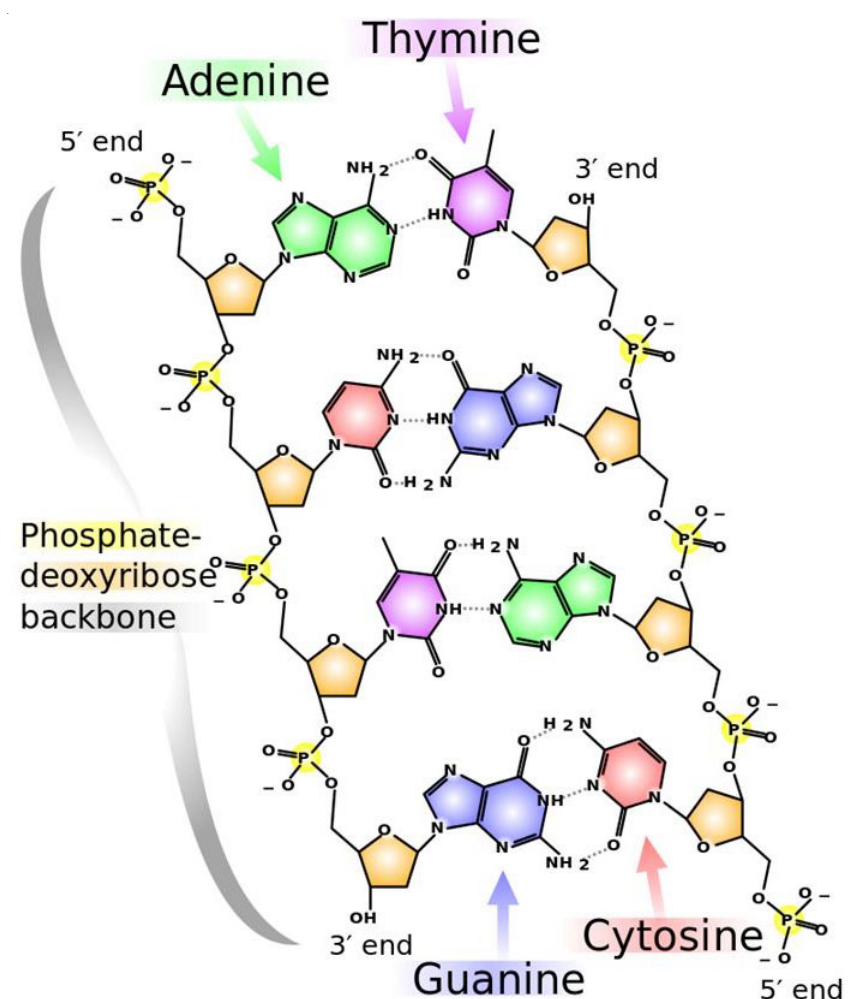

Fig. 6. A part of DNA strand showing the relatively small space available around the 3-position of guanine [Ref. 16]

As a first step towards the calculation of the transition states, an estimation of Pt- $\mathrm{N}$ and $\mathrm{Pt}-\mathrm{OH}_{2}$ distances in these structures where performed through an energy scan (Fig. 7) for Pt-N7. In Fig. 7, it can be seen that the variation of the $\mathrm{Pt}-\mathrm{OH}_{2}$ distance goes through a maximum for the Pt-N range 2.1-2.4 A corresponding to a approximate transition state. We

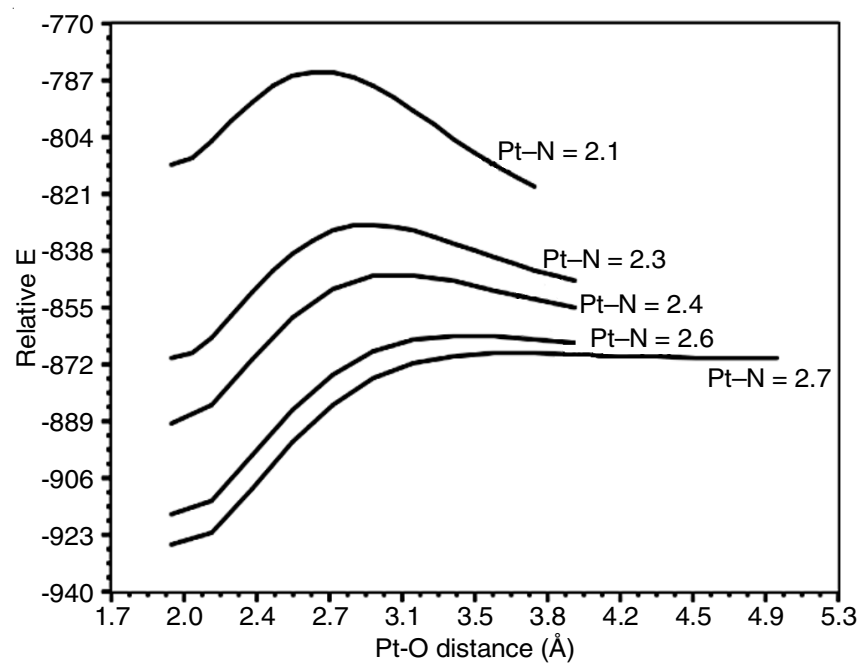

Fig. 7. Pt-N and Pt-O bond distance scan versus total energy of the reaction of aquo-cisplatin with guanine at the N7 position

chose the maxima of lowest energy i.e. at $\mathrm{Pt}-\mathrm{N}=2.4 \mathrm{~A}$ and Pt$\mathrm{OH}_{2} \sim 2.7 \mathrm{~A}$. Starting with these values, we perform complete optimization to a transition state. The final structure is given in Fig. 8. The same procedure was done for the attack at position 3, obtaining a transition state of energy $17.54 \mathrm{Kcal} / \mathrm{mol}$.

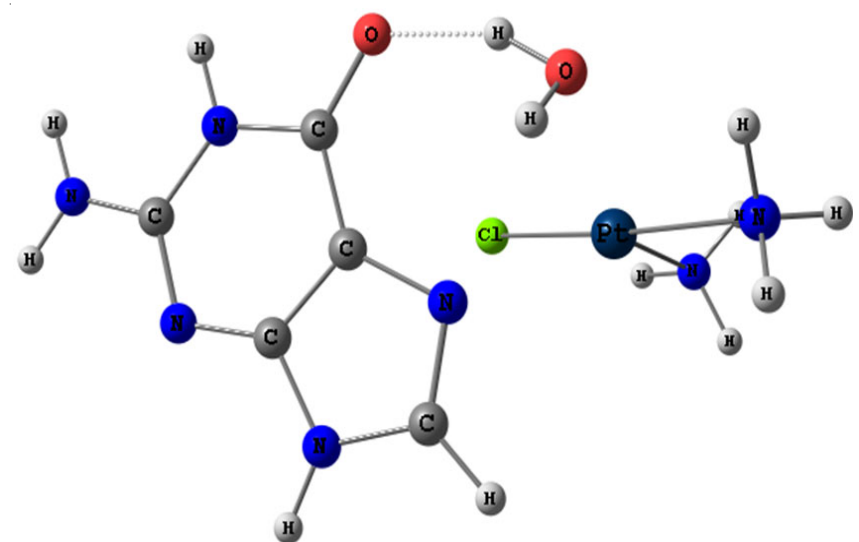

Fig. 8. Transition state of the reaction of aquo-cisplatin with guanine-N7. Activation energy $=31.75 \mathrm{Kcal} / \mathrm{mol}$

\section{Conclusion}

The trans-effect in one of the chosen platinum complexes quantitatively by computational methods is demonstrated. It was found that the activation energy due to the replacement of ammonia molecule by chloride ion in cis-[ $\mathrm{Pt}\left(\mathrm{NH}_{3}\right)_{2} \mathrm{Cl}$-cytosine] is low. The reaction of cis-platin with guanine favouring the 7-position was discussed.

\section{CONFLICT OF INTEREST}

The authors declare that there is no conflict of interests regarding the publication of this article.

\section{REFERENCES}

1. L. Kelland, Nat. Rev. Cancer, 7, 573 (2007); https://doi.org/10.1038/nrc2167.

2. Y.W. Jung and S.J. Lippard, Chem. Rev., 107, 1387 (2007); https://doi.org/10.1021/cr068207j. 
3. M.-H. Baik, R.A. Friesner and S.J. Lippard, J. Am. Chem. Soc., 125, 14082 (2003); https://doi.org/10.1021/ja036960d.

4. B. Lippert, C.J.L. Lock and R.A. Speranzini, Inorg. Chem., 20, 808 (1981); https://doi.org/10.1021/ic50217a036.

5. A. Legin, M.A. Jakupec, N.A. Bokach, M.R. Tyan, V.Y. Kukushkin and B.K. Keppler, J. Inorg. Biochem., 133, 33 (2014); https://doi.org/10.1016/j.jinorgbio.2013.12.007.

6. F. Pichierri, D. Holthenrich, E. Zangrando, B. Lippert and L. Randaccio, J. Biol. Inorg. Chem., 1, 439 (1996); https://doi.org/10.1007/s007750050076.

7. B. Lippert, Prog. Inorg. Chem., 54, 385 (2005); https://doi.org/10.1002/0471725560.ch6.

8. M. Malik and D. Michalska, Spectrochim. Acta A Mol. Biomol. Spectrosc., 125, 431 (2014); https://doi.org/10.1016/j.saa.2014.01.107.

9. B. Giese and D. McNaughton, Biopolymers, 72, 472 (2003); https://doi.org/10.1002/bip.10480.

10. T.G.I. Schaaff, Y. Qu, N. Farrell and V.H. Wysocki, J. Mass Spectrom., 33, 436 (1998); https://doi.org/10.1002/(SICI) 1096-9888(199805)33:5<436::AIDJMS649>3.0.CO;2-K.

11. M.J. Frisch, G.W. Trucks, H.B. Schlegel, G.E. Scuseria, M.A. Robb, J.R. Cheeseman, J.A. Montgomery Jr., T. Vreven, K.N. Kudin, J.C. Burant,
J.M. Millam, S.S. Iyengar, J. Tomasi, V. Barone, B. Mennucci, M. Cossi, G. Scalmani, N. Rega, G.A. Petersson, H. Nakatsuji, M. Hada, M. Ehara, K. Toyota, R. Fukuda, J. Hasegawa, M. Ishida, T. Nakajima, Y. Honda, O. Kitao, H. Nakai, M. Klene, X. Li, J. E. Knox, H.P. Hratchian, J.B. Cross, V. Bakken, C. Adamo, J. Jaramillo, R. Gomperts, R.E. Stratmann, O. Yazyev, A.J. Austin, R. Cammi, C. Pomelli, J.W. Ochterski, P.Y. Ayala, K. Morokuma, G.A. Voth, P. Salvador, J.J. Dannenberg, V.G. Zakrzewski, S. Dapprich, A.D. Daniels, M.C. Strain, O. Farkas, D.K. Malick, A.D. Rabuck, K. Raghavachari, J.B. Foresman, J.V. Ortiz, Q. Cui, A.G. Baboul, S. Clifford, J. Cioslowski, B.B. Stefanov, G. Liu, A. Liashenko, P. Piskorz, I. Komaromi, R.L. Martin, D.J. Fox, T. Keith, M.A. Al-Laham, C.Y. Peng, A. Nanayakkara, M. Challacombe, P.M. W. Gill, B. Johnson, W. Chen, M.W. Wong, C. Gonzalez and J. A. Pople, Gaussian 03, Revision C.02, Gaussian, Inc., Wallingford CT (2004).

12. J.B. Foresman and A.E. Frisch, Exploring Chemistry with Electronic Structure Methods, Gaussian, Inc., Pittsburgh, PA, edn 2 (1996).

13. K. Raghavachari, J. Chem. Phys., 88, 1688 (1988); https://doi.org/10.1063/1.454147.

14. C. Gonzalez and H.B. Schlegel, J. Chem. Phys., 90, 2154 (1989); https://doi.org/10.1063/1.456010.

15. D.P. Bancroft, C.A. Lepre and S.J. Lippard, J. Am. Chem. Soc., 112, $6860(1990)$

https://doi.org/10.1021/ja00175a020.

16. P.B. Madeleine, https://en.wikipedia.org/wiki/DNA. 